\title{
БАЗОВЫЙ МОДУЛЬ МАНИПУЛЯТОРНОЙ МАШИНЫ МНОГООТРАСЛЕВОГО НАЗНАЧЕНИЯ Мазуркин П.М.
}

Ключевые слова: манипуляторная машина, сборочные единицы, базовый модуль. Аннотация. По патенту 2522496 Российской Федерации приведено краткое описание универсальной для многих типов манипуляторных машин базового модуля.

\section{BASE MODULE MANIPULATOR MACHINES CONSUMER APPOINTMENTS Mazurkin P.M.}

Keywords: manipulator machine, assembly units, the base unit.

Abstract. According to Patent 2522496 Russian Federation is a brief description of the universal for many types of base module manipulators machines.

Изобретение [2] относится к манипуляторным машинам и комплексам многоотраслевого назначения и может быть использовано в модульных конструкциях экскаваторов, а также лесных, сельскохозяйственных, землеройных, торфяных, мелиоративных, водных, горных, строительных, дорожно-строительных, подъемно-транспортных и иных машинах и технических комплексах с манипуляторами и рабочими органами на них.

Новизна заключается в том, что полноповоротная платформа расчленена на функциональные два модуля. Опора стрелы преобразована в базовый модуль для сборки манипуляторных машин. Устройство является пионерным. От него можно будет развить множество патентоспособных устройств для формирования системы модульных манипуляторных машин.

В общем случае манипуляторная машина состоит из четырех основных частей: движителя с монтажной площадкой; базового модуля с опорно-поворотным устройством на монтажной площадке; полноповоротной подвижной платформы с механизмами и агрегатами гидросистемы и кабиной оператора; рабочего оборудования со шлейфом манипуляторов и семействами рабочих органов к каждому типу манипулятора.

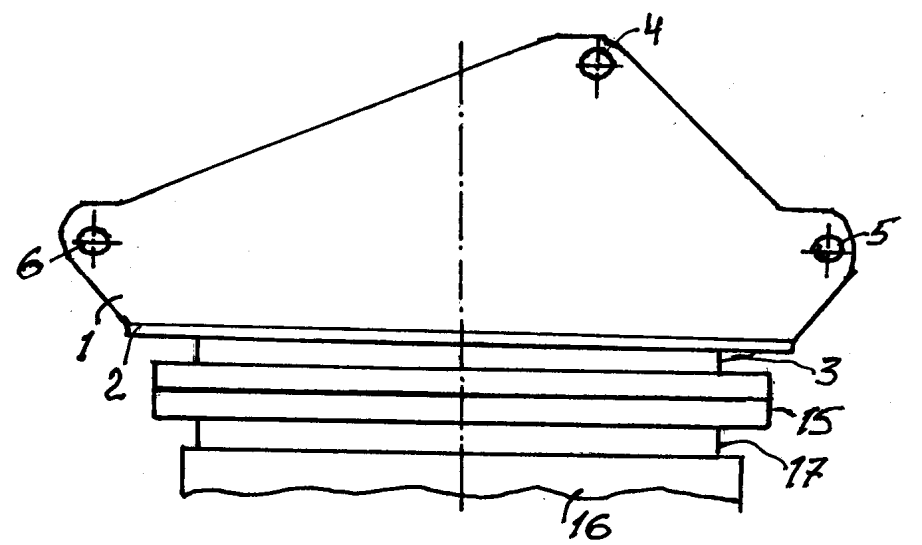

Рис. 1. Базовый модуль, вид сбоку, установленный на монтажной площадке

Базовый модуль (рис. 1, рис. 2) содержит две пары опорных пластин 1 на нижней плите 2, к которой снизу приварено крепежное кольцо 3. Пары опорных пластин снабжены отверстиями со стаканами 4 для крепления пальцами хвостовиков стрелы. На пластинах имеются также от- 
верстия со стаканами 5 для монтажа гидроцилиндров поворота стрелы манипулятора. На задней части опорных пластин для монтажа двух звеньев плоскопараллельного механизма качания полноповоротной платформы выполнены отверстия со стаканами 6 .

Внутри каждой пары опорных пластин размещены хвостовик 7 стрелы манипулятора, гидроцилиндр 8 поворота стрелы манипулятора, а в задней части базового модуля в отверстии со стаканом расположено звено 9 плоскопараллельного механизма качания полноповоротной платформы. Между этим звеном и концом хвостовика стрелы расположена тяга 10 (рис. 3).

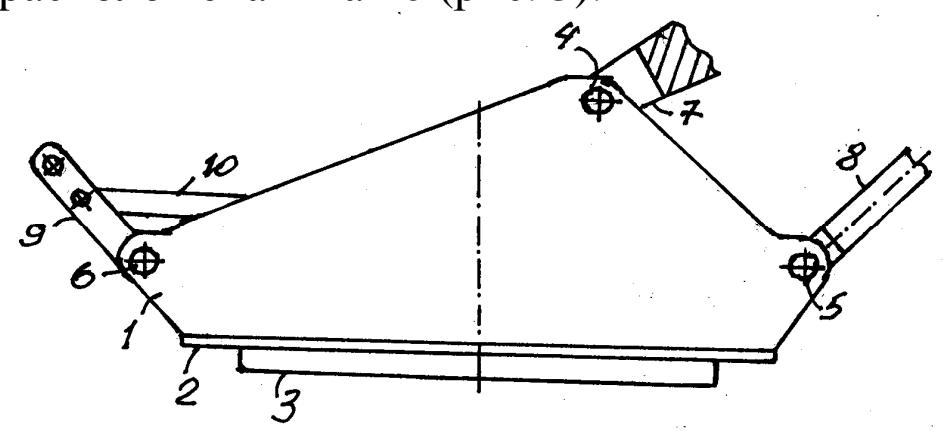

Рис. 3. Базовый модуль с одной парой опорных пластин, внутри размещены хвостовик стрелы манипулятора, тяга и одно звено плоскопараллельного механизма, а спереди гидроцилиндр поворота стрелы

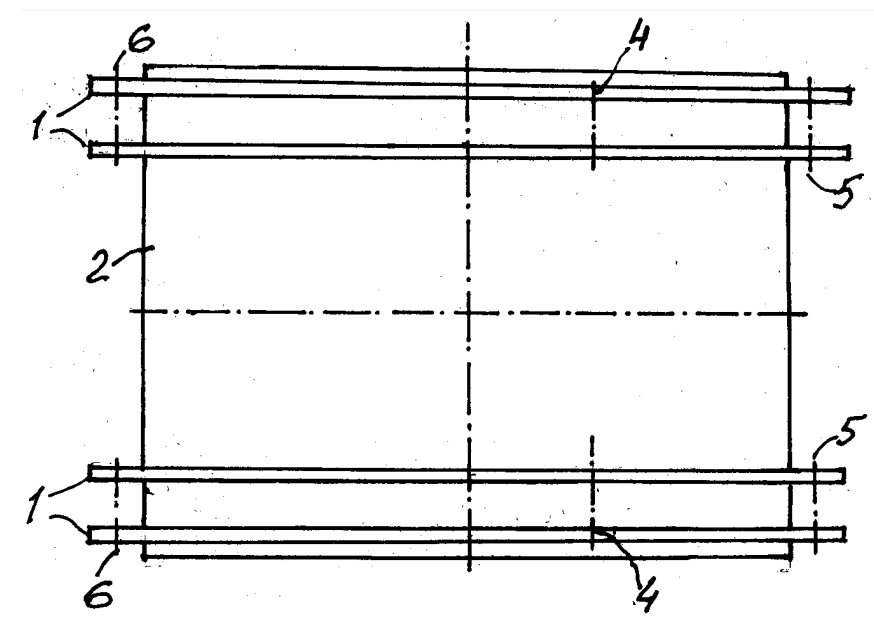

Рис. 2. Вид сверху на базовый модуль манипуляторной машины

На пальце крепления гидроцилиндра 8 поворота стрелы манипулятора снаружи базового модуля установлено звено 11 плоскопараллельного механизма качания платформы. Все четыре звена имеют одинаковую длину, что позволяет выполнять плоскопараллельное движение платформы 12 через закрепленные на ней стойки 13. Полноповоротная платформа выполнена Побразной формы с внутренней полостью 14, охватывающей с зазором предлагаемый базовый модуль. Эта полость может быть больше диаметра роликового подшипника 15 опорно-поворотного устройства. На монтажной площадке 16 приварено крепежное кольцо 17 для болтового соединения с опорно-поворотным устройством.

Базовый модуль манипуляторной машины, например, с рабочим манипуляторным оборудованием для валки и формирования пачки срезанных лесных деревьев, работает в тяжелом режиме. Для снижения габаритной высоты машины без манипулятора длины хвостовиков стрелы, тяг и звеньев подбираются так, чтобы угол качания был симметричным от вертикали. При выдвижении (рис. 4) захватно-срезающего органа вперед к корневой шейке захватываемого, подтягиваемого и затем срезаемого лесного дерева стрела манипулятора наклоняется вперед, а два хвостовика 7 - назад. 
В этом случае две тяги 10 толкают звенья 9 назад и центр тяжести полноповоротной платформы 12 , с находящимися на ней механизмами и агрегатами гидросистемы и кабиной оператора, также отходит о верти-

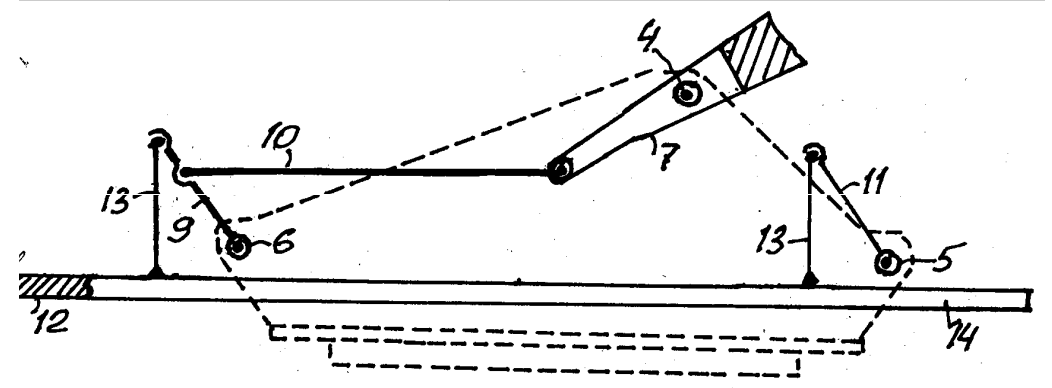

Рис. 4. Кинематическая схема асинхронной конструктивной связи между стрелой и полноповоротной качающейся платформой при максимальном вылете рабочего органа кальной оси манипуляторной машины. В итоге происходит динамическое уравновешивание момента от опрокидывающих вперед сил.

При втягивании (фиг. 5) захватно-срезающего органа со срезанным и поднятым деревом к кабине, стрела манипулятора наклоняется вверх и назад, а два хвостовика 7 отклоняются вперед.

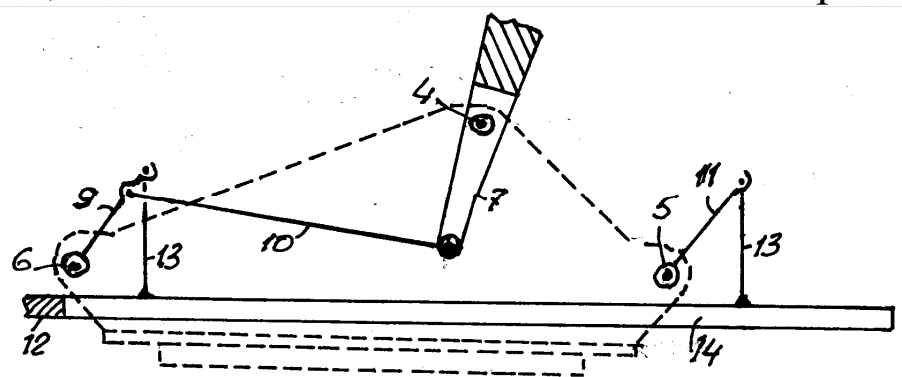

Рис. 5. Кинематическая схема асинхронной конструктивной связи между стрелой и полноповоротной качающейся платформой при минимальном вылете рабочего органа

В этом случае две тяги 10 тянут звенья 9 вперед и центр тяжести полноповоротной платформы 12 , с находящимися на ней механизмами и агрегатами гидросистемы и кабиной оператора, также приходит к вертикальной оси манипуляторной машины, то есть снижается расстояние до центра тяжести всей машины. В итоге происходит динамическое уравновешивание момента от опрокидывающих назад сил.

\section{Список литературы}

1. Мазуркин П.М. Манипуляторные машины. Учеб. пос. ЙошкарОла: МарГТУ, 2001. 354 с.

2. Пат. 2522496 Российская Федерация, МПК Е 02 F 3 / 627, В 66 С 23 / 08 (2006.01). Базовый модуль манипуляторной машины / Мазуркин П.М.; заявитель и патентообладатель Поволжский гос. технолог. ун-т. №2012148994/03; заявл. 16.11.2012; опубл. 20.07.2014. Бюл. № 20.

\section{References}

1. Mazurkin PM Manipulator machine. Yoshkar-Ola: MarSTU, 2001. 354 p.

2. Pat. 2522496 Russian Federation, IPC E 02 F 3/627, B 66 C 23/08 (2006.01). Basic module manipulator machine / Mazurkin P.M.; Volga state. technologist. Univ. publ. 07/20/2014. Bull. Number 20. 